\title{
MYOPATHY: AS AN INITIAL PRESENTATION OF HYPOTHYROIDISM IN TWO CASES OF AUTOIMMUNE THYROIDITIS
}

\author{
MD ABUL KALAM AZAD ${ }^{1}$, SHAHEEN LIPIKA QUAYUM ${ }^{2}$, MD SHAMSUL HAQUE ${ }^{3}$, LT. COL. MD. \\ AZIZUL ISLAM $^{4}$, KAK AZAD ${ }^{5}$, ANUP KUMAR SAHA ${ }^{6}$, TOFAYEL AHMED ${ }^{7}$
}

\begin{abstract}
:
Although hypothyroidism may cause a wide range of muscle disturbances, an overt myopathy may rarely present as an isolated initial presentation of hypothyroidism. The frequency of myopathy in hypothyroidism ranges from 30 to $80 \%$. The major muscular symptoms are weakness, muscular cramps and myalgia. Laboratorial investigation generally shows increased levels of muscle enzymes and low serum thyroid hormones, with high thyrotrophic-stimulating hormone (TSH) elevated. The electrophysiological study reveals myopathy, neuropathy or mixed pattern. The treatment consists in hormone replacement and the prognosis is good in most of the cases. We report two cases that developed cramps, myalgia, and weakness, one of them presented as a polymyositis-like syndrome. The muscle enzymes were increased with a raised level of TSH. The myopathy was the initial manifestation of hypothyroidism in these cases. Both the patient was treated by replacement of thyroxin with significant clinical and biochemical improvement.
\end{abstract}

\section{Introduction}

The thyroid hormone is necessary to cell metabolism of all organic systems. Its deficiency is manifested by a wide range of systemic manifestations with insidious onset ${ }^{1}$.Thyroid dysfunction may cause a wide range of muscle disturbances. Thyroid myopathy is responsible for $5 \%$ of acquired myopathies, and an overt myopathy has been rarely reported as an isolated clinical presentation of hypothyroidism ${ }^{1,2}$. Neuromuscular symptoms, such as proximal muscle weakness, fatigue, myalgia and cramps are present in $30-80 \%$ of patients with hypothyroidism ${ }^{3,4}$.

These symptoms may be subtle with only decreased and delayed tendon reflexes to pronounced muscle weakness, hypertrophic, painful and stiff muscles ${ }^{5,6,7}$. The typical hypothyroid myopathy presents as mild weakness of the pelvic-shoulder girdle muscles ${ }^{8}$.

The myopathy associated with hypothyroidism could be divided in four subtypes: Kocher- Debré-Semelaigne syndrome, Hoffman's syndrome, atrophic form and myasthenic syndrome. In the Kocher- Debré-
Semelaigne syndrome described in infants with cretinism, as in the Hoffman's syndrome, patients presented with hypertrophy, muscular weakness, slowness of mental and locomotor activities. In Hoffman's syndrome, muscular cramps, post- exercise stiffness and pseudomyotonic phenomenon are also present. Other less frequent presentations are atrophic myopathy and myasthenic syndrome unsatisfactory response to edrophonium ${ }^{9,10}$.

Polymyositis-like syndrome, with proximal muscle weakness and elevation of muscle enzymes, may also be a clinical manifestation of hypothyroidism. Due to the similarity of biochemical and clinical findings, this condition is easily confused with classic polymyositis which is an autoimmune inflammatory muscle disease with symptoms of proximal muscle weakness and pain ${ }^{11}$. Active polymyositis is almost always associated with an elevation of one or more sarcoplasmic enzymes (creatine phosphokinase, aldolase, transaminase, lactate dehydrogenase), especially the transaminases and creatine phosphokinase (CPK) together with a high erythrocyte sedimentation rate and myoglobinuria ${ }^{12}$.

1. Assistant Professor of Medicine, Bangabandhu Sheikh Mujib Medical University, Dhaka.

2. Assistant Professor of Pharmacology, Pioneer Dental College, Dhaka.

3. Associate Professor \& Head, Department of Opthalmology, Faridpur Medical College, Faridpur.

4. Medicine Specialist, CMH, Bogra Cantonment, Bogra

5. Associate Professor, Department of Medicine, Bogra Medical College

6. Consultant (Medicine), Central Police Hospital, Dhaka

7. Professor \& Chairman, Department of Medicine, BSMMU, Dhaka 
One particular difficulty in the diagnosis of polymyositis-like syndrome is that both hypothyroidism itself and polymyositis in euthyroid patients may manifest with weakness, changes in swallowing, speech and voice, arthritis/arthralgia, altered bowel habits and elevated muscle enzymes ${ }^{13}$. Once the hormonal deposition is started, the myopathy could be reversible with good prognosis.

Here we present two cases of Hashimoto's thyroiditis, where myopathy was the initial presentation, one of which was presented with polymyositis -like syndrome and other was presented as a case of classic myopathy. Classic symptoms/signs of hypothyroidism such as lethargy, constipation, cold intolerance, myxedematous facies, and/or bradycardia were absent in one case.

\section{Case report 1:}

A young lady aged 27 years, mother of one child presented on 03/03/07 with progressive myalgia and tingling in both hand for four months. She had no history of fever, fatigue, arthralgia, arthritis, or weight gain. On query she gave the history of SLE of her mother. Physical examination revealed a welldeveloped young lady with normal vital signs. Examination of the heart, lungs, abdomen and extremities were unremarkable. On neurological examination her mental status and cranial nerve findings were normal. Muscle tenderness was present with palpation. Moderate weakness was present in the proximal muscles of the lower limb without atrophy, fasciculations or other neurological deficit, except delayed relaxation of ankle jerks. The relaxation phase of Achilles tendon reflex was mildly prolonged, her sensation and reflex examination were normal. Her gait was normal but she was hardly able to arise from a squatting position unassisted. There was no skin rash, arthritis/ arthralgia and the thyroid gland was normal with palpation and considered she was a provable case of polymyositis.

On investigation her haemogram including erythrocyte sedimentation rate $(18 \mathrm{~mm} / \mathrm{h})$, CRP, urine RE, blood sugar, renal function test, lipid profile and serum electrolytes were within normal range. Muscle enzymes i.e. aspartate aminotransferase (AST) and creatine phosphokinase (CPK) were significantly elevated (Table-1).
Table 1

Levels of muscle enzymes of case 1

\begin{tabular}{|c|c|c|c|}
\hline & $\begin{array}{c}\text { AST } \\
\text { (N: up to } \\
40 \mathrm{U} / \mathrm{L})\end{array}$ & $\begin{array}{c}\text { CPK } \\
\text { (N: up to } \\
190 \mathrm{U} / \mathrm{L})\end{array}$ & $\begin{array}{c}\text { Serum Aldolase } \\
(\mathrm{N}: \text { upto } \\
6.5 \mathrm{U} / \mathrm{L})\end{array}$ \\
\hline $04 / 03 / 07$ & 116 & 884 & 7.8 \\
\hline $31 / 5 / 07$ & 32 & 240 & 4.3 \\
\hline
\end{tabular}

We looked for auto antibodies (Rheumatoid factor, ANA, anti-ds DNA, anti- RNP, and anti- Jo-1). The results were normal except for ANA, which was initially positive (sample value: $32.5 \mathrm{U} / \mathrm{L}$ and reference value: ${ }^{3} 10+v e$ ). Her serum free thyroxin (FT4) was $0.04 \mathrm{ng} / \mathrm{dl}$ (normal: 0.8-1.9 $\mathrm{ng} / \mathrm{dL}$ ), free triiodothyronine (FT3) concentration was $0.11 \mathrm{pg} /$ $\mathrm{ml}$ (normal: $1.5-4.1 \mathrm{pg} / \mathrm{ml}$ ) and TSH was $>40.00 \mathrm{mIU} /$ $\mathrm{L}$ (normal 0.47-5.01 $\mathrm{mIU} / \mathrm{L}$ ). Anti thyroid peroxidase (anti- TPO) was positive $(355 \mathrm{IU} / \mathrm{ml}$, normal: $<35$ $I U / m l)$. Her other blood biochemistry levels were normal. The EMG was normal. As her all other antibodies, except ANA was negative, muscle biopsy was not done. Since her clinical condition and biochemical profile (Table 1) responded well to thyroid replacement therapy and she was diagnosed as possible polymyositis-like syndrome associated with hypothyroidism due to Hashimoto's thyroiditis, where painful myopathy was the only initial clinical manifestation. She was assessed and followed up for raised ANA. She was treated with oral thyroxin in incremental dose, and finally dose was adjusted to $2 \frac{1}{2}$ tab/day. After initiation of treatment, TSH reverted to normal ( $1.79 \mathrm{mIU} / \mathrm{L})$. On $9^{\text {th }}$ September, ANA was negative (sample value: $8.10 \mathrm{U} / \mathrm{ml}$ ).

\section{Case report 2:}

A 38 year-old diabetic male on medication presented on $3^{\text {rd }}$ March, 2007 with undue tiredness, progressive weight gain with severe myalgia for 5 months. His diabetes was well controlled with metformin until 03/01/07. Thereafter his blood sugar was not monitored. He noticed progressive weight gain as evidenced by increased abdominal girth without any change in appetite or bowel habit. On examination he had facial edema and alteration of voice. Hair texture was coarse, lusterless with rough skin. His blood pressure was $130 / 80 \mathrm{mmHg}$ with pulse rate 66/ minute. Neurological examination didn't reveal any significant abnormality except slight weakness in rising from squatting position and delayed relaxation of the ankle jerks. Other systems including musculoskeletal system were intact. 
Table-2

Some biochemical markers of case-2

\begin{tabular}{lcccccc}
\hline & TSH & CPK & $\begin{array}{c}\text { Total } \\
\text { Cholesterol }\end{array}$ & $\begin{array}{c}\text { HDL- } \\
\text { cholesterol }\end{array}$ & $\begin{array}{c}\text { LDL- } \\
\text { Cholesterol }\end{array}$ & Triglycerides \\
\hline $\begin{array}{l}\text { Normal } \\
\text { value }\end{array}$ & $\begin{array}{c}0.4-4.0 \\
\mu \mathrm{IU} / \mathrm{ml}\end{array}$ & $\begin{array}{c}\text { Upto } \\
171 \mathrm{U} / \mathrm{L}\end{array}$ & $\begin{array}{c}<5.2 \mathrm{mmol} / \mathrm{l} \\
\text { desirable }\end{array}$ & $\begin{array}{c}>1.45 \mathrm{mmol} / \mathrm{l} \\
\text { No risk }\end{array}$ & $\begin{array}{c}<2.6 \\
\mathrm{mmol} / \mathrm{l}\end{array}$ & $\begin{array}{c}0.57-1.7 \\
\mathrm{mmol} / \mathrm{l}\end{array}$ \\
\hline $03 / 03 / 07$ & $>75$ & 461 & 11.1 & & & \\
$06 / 04 / 07$ & 49.9 & & & & & \\
$08 / 06 / 07$ & 3.54 & 83 & 3.53 & 0.61 & 1.97 & 5.25 \\
\hline
\end{tabular}

His haemoglobulin was $15 \mathrm{gm} / \mathrm{dl}$ with normal total and differential count of WBC, and ESR was $10 \mathrm{~mm}$ in $1^{\text {st }}$ hour. His blood biochemistry revealed normal RBS (6.53 mmol/l), SGPT (35 U/L), serum creatinine $(85 \mu \mathrm{mol} / 1)$, and serum electrolytes. Serum CPK was $461 \mathrm{U} / \mathrm{L}$. Serum Aldolase was $6.8 \mathrm{U} / \mathrm{L}$ with high total cholesterol (sample value: $11.1 \mathrm{mmol} / \mathrm{l},<5.2 \mathrm{mmol} /$ 1 desirable). Serum free thyroxin (FT4) was $0.01 \mathrm{ng} /$ dl (normal: 0.8-1.9 $\mathrm{ng} / \mathrm{dL}$ ), free triiodothyronine (FT3) concentration was $0.1 \mathrm{pg} / \mathrm{ml}$ (normal: $1.5-4.1$ $\mathrm{pg} / \mathrm{ml}$ ) TSH level was $>75.0 \mu \mathrm{IU} / \mathrm{mL}$. Anti-TPO was positive $(278 \mathrm{IU} / \mathrm{ml}$, normal: $0-34 \mathrm{IU} / \mathrm{ml})$. ANA was within normal limit. The EMG was myopathic with severe weakness. He was diagnosed as case of Diabetes mellitus with hypothyroid myopathy due to Hashimoto's thyroiditis. He was treated with thyroxin which was gradually builded up to $150 \mu \mathrm{g} /$ day, atorvastatin $20 \mathrm{mg} /$ day with his previous medication. With this treatment he was symptomatically and biochemistry reverted to near normal (table-2). Dose of atorvastatin was reduced to $10 / \mathrm{mg}$ / day and fenofibrate $200 \mathrm{mg} /$ day was added.

\section{Discussion:}

The neurological manifestations of hypothyroidism usually occur after clinical manifestations of other symptoms. Primary hypothyroidism accounts for 95\% of hypothyroidism. Hashimoto's thyroiditis, an autoimmune chronic disease is the main etiology of hypothyroidism, so we didn't do anti-thyroglobulins. It is associated with high level of antiperoxidase antibodies (positive in 90-100\% cases) and antithyroglobulins (positive in $80-90 \%$ cases). Anti-TPO was positive in both the cases. The first description of muscle dysfunction in hypothyroidism was from Ord in 1879. Since there have been multiple reports of muscle weakness or other abnormalities associated with hypothyroidism ${ }^{11,14}$.
Musculoskeletal symptoms may predominate and may be the only presenting feature of hypothyroidism ${ }^{2}$. A wide spectrum of muscle abnormalities exists in hypothyroidism, ranging from the classic delay in deep tendon reflexes to a variable degree of weakness, muscle stiffness and increased muscular mass. However, in both the cases of severe hypothyroid myopathy, especially in the $1^{\text {st }}$ case with positive family history of SLE, initially she was diagnosed as a case of polymyositis with the similar presenting clinical and laboratory features such as proximal muscle weakness and elevated serum muscle enzymes. But clinical response to thyroxin is the main clue for diagnosis of hypothyroid myopathy ${ }^{11,14}$.

Hypothyroidism reduces the ability of the muscle to maintain its adequate energetic economy, via several suggested mechanisms. This may lead to injury (myopathy) and elevation of serum CPK levels. The pathogenesis of this CPK elevation is not well understood, but may be caused by a reversible defect in glycogenolysis, direct cell damage, and /or reduced metabolic clearance of $\mathrm{CPK}^{11,12,15}$. But there is no correlation between the evolution time of hypothyroidism, hormonal levels, CPK increase, and muscular weakness ${ }^{16}$. There is reduced protein synthesis, but protein catabolism is also diminished ${ }^{17}$. The presence of triiodothyronine receptor on the mitochondrial membrane of skeletal muscle suggests a direct impact of thyroid hormones on oxidative metabolism and may provide a biochemical basis for the muscle dysfunction in hypothyroidism. Even severe hypothyroidism may reduce glycolysis and oxidative phosphorylation and thus reduces adenosine triphosphate concentrations beyond a critical limit, generating a marked release of $\mathrm{CPK}$ through the altered sarcolemmal membrane ${ }^{18,19}$. 
Exercise intolerance could be due to an abnormal recruitment of several metabolic pathways related to the mitochondrial metabolism impairment. Abnormal accumulation of protons and ions, which are involved in the actin-myosin interaction, as well as abnormal $\mathrm{Ca}^{++}$metabolism leads to reduced exercise tolerance ${ }^{5,20}$. Our patients also had a high level of CPK with exercise intolerance like proximal muscle weakness and some trouble in climbing stairs and rising from a chair, although they were able to continue his normal daily activities.

Both the patients were treated with oral synthetic thyroid hormone, in the form of thyroxin. We evaluated and monitored the patients for cardiovascular risks. It should be kept in mind that, some patient with severe myopathic manifestations may deteriorate in the beginning of the treatment, probably caused by the raise of metabolic demand induced by thyroxin. In these cases, concomitant use of steroid during some time of the treatment may act as membrane- stabilizing effect ${ }^{10}$.

The characteristics of polymyositis-like syndrome in hypothyroidism do not differ from those of nonspecific hypothyroid myopathy; therefore clinical judgment alone may not be sufficient to suspect this syndrome. Since the presentation of hypothyroidism may be with polymyositis-like syndrome, so our recommendation is serum TSH levels should be routinely tested in all patients with muscle weakness or elevation of CPK.

\section{References:}

1. Bradley WG, Daroff R, Fenichel G, Marsden CD. Neurology in clinical practice. $3^{\text {rd }}$ ED. Boston: Butterworth Heinemann 2000; 1009-1034.

2. Rodolico C, Toscano A, Benvenga S, Mazzeo A, Bartolone S, Bartolone L. Myopathy as the persistently isolated symptomatology of primary autoimmune hypothyroidism. Thyroid 1998; 8(11):1033-8.

3. Çakir M, Samanci N, Balci N, Balci MK. Musculoskeletal manifestations in patients with thyroid disease. Clin Endocrinology 2003; 59:162167.

4. Duffy RF, Bosch JV, Laman DM, Loon BJP, Linseen WHJP. Neuromuscular findings in thyroid dysfunction: a prospective clinical and electrodiagnostic study. J Neurol Neurosurg Psychiatry 2000; 68:750-755.

5. Amato AA. Endocrin Myopathies and Toxic Myopathies. Ed: Brown WF, Bolton CF, Aminof MJ, Neuromuscular Function and Disease. Basic, Clinical and Electrodiagnostic Aspects. Vol 2, 78:1399-1402, Saunders Company, Philadelphia, 2002.

6. Kisakol G, Tunc R, Kaya A. Rhabdomyolysis in a patient with hypothyroidism. Endocrine J 2003; 50(2): 221-223.

7. Brian AC, Bolton CF: Peripheral Neuropathy in Systemic Disease. Ed: Brown WF, Bolton CF, Aminof MJ, Neuromuscular Function and Disease. Basic, Clinical and Electrodiagnostic Aspects. Vol 2, 60:1081-1086, Saunders Company, Philadelphia, 2002 .

8. Klein I., Ojamaa K. Thyroid (neuro) myopathy. The Lancet, Commentary 2000; 356:614.

9. Mckeran RO, Slavin G, Ward P, Paul E, Mair WGP. Hypothyroid myopathy: a clinical and pathological study. J Pathol 1980; 132: 35-54.

10. Vasconcellos LFR, Peixoto MC, Nunes de Oliveira T, Penque G, Leite ACC. Hoffman's syndrome: pseudohypertrophic myopathy as initial manifestation of hypothyroidism. Arq Neuropsiquiatr 2003; 61(3B):851-54.

11. Madariaga M. Polymyositis-Like syndrome in hypothyroidism: review of cases reported over the past twenty-five tears. Thyroid 2002; 12(4):331-36.

12. Scott KR, Sýmmons Z, Boyer PJ. Hypothyroid myopathy with a strikingly elevated serum creatine kinase level. Muscle Nerve 2002; 26:141-44.

13. Cinamon U. Exceptionally elevated creatine kinase levels in a laryngectomized patient: hypothyroid myopathy. J Laryngology \& Otology 2004; 118: 651652.

14. Hochberg MC, Koppes GM, Edwards CQ, Barnes HV, Arnett FC. Hypothyroidism presenting as a polymyositis-like syndrome. Arthritis Rheum, 1976; 19(6):1363-1366.

15. Yuksel G, Akpinar A, Comez N, Orken C, Tireli HT. Hypothyroidism Presenting as a Polymyositis-Like Syndrome (Case Report). J Neurol Sci 2007; 24(3): 244-249. 
16. del Palacio A, Trueba JL, Cabello A, Gutiérrez E, Moya I, Fernández MC, et al. Hypothyroid myopathy, clinico-pathologic study of 20 cases. An Med Interna 1990; 7(3):115-9.

17. Ono S, Inouye K, Mannen T. Myopathology of hypothyroid myopathy. J Neurol Sci 1987; 77:237-248.

18. Claus T, Elitok S, Schmitt R, Luft FC, Kettritz R. Thyroid function and glomerular filtration- a potential for grave errors. Nephrol Dial Transplant 2005; 20: 1002-1003.
19. Mastropasqua M, Spagna G, Baldini V, Tedesco I, Paggi A. Hoffman's syndrome: muscle stiffness, pseudohypertrophy and hypothyroidism. Horm Res. 2003; 59(2):105-8.

20. Lochmüller H, Reimers CD, Fischer P, Heub D, Müller-Höcker J, Pongratz DE. Exercise-induces myalgia in hypothyroidism. Clin Investing 1993; 71:999-1001. 